\title{
Comparative Study Regarding Functional and Radiological Outcomes of Different Modes of Fixation for Distal Femur Fracture
}

\author{
Dipak Kumar Jha1 ${ }^{1}$, Atanu Chatterjee², Prashanta Kumar Pujari³ ${ }^{3}$, Siddharta Mahapatra ${ }^{4}$
}

\begin{abstract}
${ }^{1}$ Department of Orthopaedics, Vivekananda Institute of Medical Sciences, Kolkata, West Bengal, India. ${ }^{2}$ Department of Orthopaedics, Vivekananda Institute of Medical Sciences, Kolkata, West Bengal, India. ${ }^{3}$ Department of Orthopaedics, Vivekananda Institute of Medical Sciences, Kolkata, West Bengal, India. ${ }^{4}$ Department of Orthopaedics, Vivekananda Institute of Medical Sciences, Kolkata, West Bengal, India.
\end{abstract}

\section{ABSTRACT}

\section{BACKGROUND}

Treatment of distal femur fractures has recently evolved towards indirect reduction and minimally invasive techniques. The goal is to strike a balance between the mechanical stability of the fragments and the biological viability. Advent of MIPO technique has reduced the amount of soft tissue injury, delayed healing, tissue necrosis and infections. The objective was to compare the functional and radiological outcome of fracture distal femur treated by open reduction with LCP by minimally invasive plate osteosynthesis (MIPO). We wanted to compare the clinical and radiological differences between open and MIPO techniques for distal femoral fracture fixation.

\section{METHODS}

This was a prospective interventional study. 41 subjects with closed supracondylar femur fracture treated surgically from March 2013 to December 2017, were evaluated prospectively for functional and radiological outcome results after fixation with distal femoral locking compression plate in open or minimally invasive way, with minimum follow up of 1 year. IBM SPSS Ver. 25 software was used to perform statistical analysis.

\section{RESULTS}

The mean age of 41 treated patients was $53.8 \pm 13.7$ years and ranged from 23 to 84 years. 19 patients were females and 22 were males. Mean time to surgery was $5.7 \pm$ 2.9 days with minimum 2 and maximum of 18 days from injury. Initially 20 patients underwent open surgery and 21 patients were operated by minimally invasive plating technique. In all cases, a 316L stainless steel alloy distal femoral locking plate was used.

\section{CONCLUSIONS}

Knee ROM could be started at a mean of 1.4 weeks earlier in the MIPO group and this was statistically significant. The two groups did not differ significantly in start of full weight bearing. Knee flexion at 6 weeks was also comparable in the two groups. However, knee flexion was average $21.9^{\circ}$ higher in MIPO group at 1 year which was significantly different than ORIF group. The proportion of patients with $>90^{\circ}$ and $>110^{\circ}$ knee flexion also varied significantly between the groups. VAS score in MIPO group was significantly less at 6 weeks but difference was non-significant at 1 year. There were 2 cases with non-union and implant failure in the ORIF group, but the proportion was not significant. There was $10^{\circ} \mathrm{FFD}$ in 1 patient of ORIF group, while varus deformity occurred in 3 patients of MIPO group. The proportion of deformity was not significantly different between the two groups.

\section{KEY WORDS}

Supracondylar Femur Fracture, LCP, MIPO, Open Reduction Internal Fixation, Intraarticular Fractures, VAS Score
Corresponding Author: Dr. Atanu Chatterjee, V2-14 Quarters, Ramakrishna Mission Seva Pratishthan, Vivekananda Institute of Medical Sciences, 99-Sarat Bose Road, Kolkota-700026, West Bengal, India. E-mail: atanuchatterjee1987@gmail.com

DOI: $10.14260 / \mathrm{jemds} / 2020 / 113$

Financial or Other Competing Interests: None.

How to Cite This Article:

Jha DK, Chatterjee A, Pujari PK, et al. Comparative study regarding functional and radiological outcomes of different modes of fixation for distal femur fracture. J. Evolution Med. Dent. Sci. 2020;9(08):502507, DOI: $10.14260 /$ jemds/2020/113

Submission 09-12-2019, Peer Review 30-01-2020, Acceptance 05-02-2020, Published 24-02-2020.

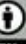




\section{BACKGROUND}

Distal femoral fractures accounts for about $7 \%$ of all femur fractures. A bimodal age distribution is noticed, with a high incidence in young adult population from high energy trauma such as motor vehicle accidents or fall from height, and a second peak in the elderly due to the poor quality of bone in this age group. Open fractures occur in $5 \%$ to $10 \%$ of all distal femur fractures. ${ }^{1-3}$ Most distal femoral fractures are result from severe axial load along with the varus, vulgus or rotational forces. Distal femur fractures are associated with high energy trauma such as road traffic accident and fall from height in young and osteoporosis in elderly. 4,5 Outcome of distal femoral fracture treatment depends upon the several patient and injury related variables like age, open fracture, infection, obesity, presence of co-morbidities, smoking and degree of comminution. Several classification systems are available for the distal femoral fractures. ${ }^{6-8}$ AO Muller classification system is considered to be the best because it deals with the severity of bone lesion and thus served as a basis for treatment and for evaluation of the results.9,10

Before 1970 maximum fractures are treated with conservative means like traction to get an acceptable functional outcome. But it predisposes patients to have a prolonged period of immobilization and impaired functional state of them. Displaced femoral fractures are best treated with operative stabilization. Soft tissue conditions play an important role in determining whether the fracture is to be immobilized externally or internally. Regarding internal fixation, mechanically unstable fractures of distal femur have been difficult to treat. Problems such as varus collapse, malunion, non-union, infection, frequently resulted before the introduction of Less Invasive Stabilization System (LISS) and Indirect mode of Reduction which used the concept of Minimal Invasive Plate Osteosynthesis (MIPO) were popularized.11-13 Management of distal femur fractures is a challenge to orthopaedic surgeon in general and more so in elderly patients with osteoporosis. ${ }^{13}$ Use of distal femur Locking Compression Plate (LCP) overcomes many pitfalls over the earlier implants. The LCP forms a fixed angle construct and allows placement of plate without any contact to bone, thus maintaining vascularity of the bone underneath and functions as an internal fixator. ${ }^{14-16}$ Indirect reduction relies on traction across the soft tissue to achieve reduction and use of MIPO allows for biological plating where by restoration of articular congruity, maintenance of soft tissue attachment and vascularity to the cortical bone fragment is achieved. ${ }^{17}$ For past several years, the use of MIPO technique has been accepted and increasingly used, where the plate is extraperiosteally inserted beneath the muscle, crossing over the fracture site distally onto the bone cortex and fixed by proximal and distal locking. ${ }^{18,19}$

Jain et al stated that provided it is applied with proper understanding of biomechanics, LCP is one of the best available options for management of challenging peri- and intra-articular fractures of distal femur. ${ }^{20}$ While EL-Ganainy et al concluded that minimally invasive percutaneous locked plating provided favourable results in the treatment of distal femoral fractures in geriatric population with diabetes. ${ }^{21}$ Subasi et al stated that minimally invasive percutaneous plate fixation can be considered an alternative technique in type IIIA and type IIIB open fractures resulting from high-velocity gunshot injuries. ${ }^{22}$ Farouk et al concluded percutaneous minimally invasive plating technique disrupts the femoral blood supply less than the traditional open method. Such minimally invasive methods may be more advantageous biologically than the traditional method. The advantage of MIPO and use of LCP includes limited soft tissue dissection, preservation of fracture hematoma, thereby reduce the incidence of malunion and non-union, early mobilization, thereby reducing stiffness, leading to an improvement in the union rates, even in the elderly with osteoporosis and decreased need for bone grafting.

Several reports are there showing outcome of different modes of fixation separately but very few studies are available which compare the outcome of all these mode of fixation all together to determine any protocol for further management of these distal femoral fractures. ${ }^{20-22}$ The purpose of this study is to evaluate the results of fracture lower end of femur treated by closed reduction and internal fixation using LCP by MIPO technique and to compare it with open mode of fracture fixation.

\section{METHODS}

The study protocol was submitted to the Institutional Ethics Committee. Upon review and approval, study was initiated. We have selected patients admitted in our institution from OPD and Emergency department. At diagnosis, patients were informed in a clear and comprehensive way of the type of treatment and other possible surgical and conservative alternatives. They were invited to read, understand and sign the informed consent form. Once informed consent was obtained, baseline laboratory parameters, pre anaesthetic check-up was done and the operation was planned by a senior orthopaedic surgeon. We have only included closed distal femoral fractures starting from 33A1 to 33C3 AO types, operated within 3 weeks of fracture. They have been operated all these patients from March 2013 to December 2017 and followed up while presenting in out-patient department for at least 1 year in terms of clinical and radiological parameters as a part of this prospective, non-randomized study, with all consecutive patients or emergency who were planned for surgery. Compound fractures, fractures older than 3 weeks and pathological fractures were excluded from this study. As per the previous patient directory we have taken 40 as the minimum number of subjects for the period for the proposed study. 41 patients were presented during the study period who fulfilled the inclusion and exclusion criteria. 20 patients underwent ORIF and 21 patients underwent MIPO.

\section{Surgical Technique}

All patients were operated under spinal anaesthesia. Patients were positioned supine on a radiolucent operating table. Injured limb was kept in minimal flexion at knee and normal limb was flexed at knee and abducted for creating adequate space for image intensifier. In the MIPO group, surgical approach was decided based on, whether the fracture is extraarticular or intraarticular. For extraarticular fractures, a modified standard lateral approach was used. For intraarticular fractures, a lateral parapatellar approach was used. All reductions were achieved by indirect methods. This involved using small bolsters/bumps placed underneath the distal thigh to correct sagittal plane deformities. Reduction 
clamps and traction were used to correct alignment in the coronal plane. Under image intensifier guidance, alignment and rotation were restored by judging the hip rotation on the uninjured side using the lesser trochanter as a guide. Leg length was maintained by traction. Following reduction, appropriate-sized plates (anatomically pre-contoured LCP for distal femur made of 316L stainless steel alloy was used in our study. LCP are available from 6-13 hole with plate thickness of $4.5 \mathrm{~mm}$ ) were slid in the submuscular plane holding one end of the plate with a sleeve. The plate was then aligned to the contour of the bone. After confirming the alignment of the plate with distal segment was fixed provisionally with the help of K-wire. The length of the plate was determined intraoperatively after reduction. For distal fixation, at least 3 metaphyseal locking screws were used, their sizes did not violate the intercondylar notch space. Under fluoroscopic guidance, the incision was made over the lateral aspect of the thigh at the level of the proximal screw holes. The tensor fascia lata and vastus lateralis were split in the direction of their fibres. This proximal incision was used to check the approximation of plate to bone. Reduction was sometimes maintained by Kirschner wires placed through holes in the LCP. A bridging technique was used for comminuted fractures, whereas a compression technique was used for simple fractures. Bone grafting was not performed. All proximal screws were bicortical. At least 3 screw holes were beyond the proximal extent of the fracture, and distally the plate did not extend beyond the joint line.

In the open group, we usually went for standard direct lateral or lateral parapatellar incision for exposure and direct reduction of the fracture fragments tried with bone levers and bone holding clamps applied after adequate periosteal stripping.

\section{Statistical Analysis}

IBM SPSS ver. 25 software was used to perform statistical analyses. A p-value of $<.0 .05$ was considered statistically significant. Continuous variables were summarised with mean and standard deviation and compared between the open and minimally invasive group using student t-test. Non-parametric data were compared using Wilcoxon rank sum test. Categorical variables were summarised as proportions and compared between the two groups using chi- square test.

\section{RESULTS}

In the present study of $n=41$ subjects with supracondylar femur fracture treated surgically, were evaluated prospectively for functional and radiological outcome results after fixation with distal femoral locking compression plate in open or minimally invasive way. All the patients included were followed for clinical and radiological evaluation for minimum of 12 months. The mean age of 41 treated patients was $53.8 \pm$ 13.7 years and ranged from 23 to 84 years. 19 patients were females and 22 were males. According to AO Muller classification of distal femur, 2 were A1 type, 8 were A2 type, 4 were A3 type, 2 were B1 type, 4 were B2 type, 13 were C1 type and 8 were $\mathrm{C} 2$ type. All of them are closed fractures. 15 patients had comorbidities (2 Hypertension, 2 IHD, 1 COPD and 11 having T2DM). 13 patients were immobilised with a
Thomas splint initially, 5 patients were put on below knee skin traction, 23 patients had been given a long leg slab. Mean time to surgery was $5.7 \pm 2.9$ days with minimum 2 and maximum of 18 days from injury. Initially 20 patients underwent open surgery and 21 patients were operated by minimally invasive plating technique. In all cases a Distal femoral locking plate was used. The comparison of epidemiologic and patient factors between the two approaches is summarised in table 1 .

\begin{tabular}{|c|c|c|c|c|c|c|c|}
\hline \multirow{2}{*}{\multicolumn{3}{|c|}{ Variables }} & \multicolumn{4}{|c|}{ Approach to Fixation } & \multirow{2}{*}{ p } \\
\hline & & & \multicolumn{2}{|c|}{ ORIF (n=20) } & \multicolumn{2}{|c|}{ MIPO (n=21) } & \\
\hline \multicolumn{3}{|c|}{ Age (Mean \pm SD) (Range)Years } & \multicolumn{2}{|c|}{$48.1 \pm 13.5(23-69)$} & \multicolumn{2}{|c|}{$59.3 \pm 12.1(30-84)$} & 0.01 \\
\hline \multirow{2}{*}{$\begin{array}{l}\text { Gender } \\
\text { (no (\%)) }\end{array}$} & \multirow{2}{*}{\multicolumn{2}{|c|}{$\begin{array}{l}\text { Male } \\
\text { Female }\end{array}$}} & \multirow{2}{*}{\multicolumn{2}{|c|}{$\begin{array}{l}10(50 \%) \\
10(50 \%)\end{array}$}} & \multirow{2}{*}{\multicolumn{2}{|c|}{$\frac{12(57.1 \%)}{9(429 \%)}$}} & \multirow{2}{*}{0.646} \\
\hline & & & & & & & \\
\hline \multirow{7}{*}{$\begin{array}{l}\text { AO type } \\
\text { (no (\%)) }\end{array}$} & \multirow{3}{*}{ A } & $\mathrm{A} 1$ & \multirow{3}{*}{$\begin{array}{c}6 \\
(30 \%)\end{array}$} & $2(10 \%)$ & \multirow{3}{*}{$\begin{array}{c}8 \\
(38.1 \%)\end{array}$} & $0(0 \%)$ & \multirow{7}{*}{0.127} \\
\hline & & $\mathrm{A} 2$ & & $4(20 \%)$ & & $4(19 \%)$ & \\
\hline & & $\mathrm{A} 3$ & & $0(0 \%)$ & & $4(19 \%)$ & \\
\hline & \multirow{2}{*}{ B } & B1 & \multirow{2}{*}{$\begin{array}{c}1 \\
(5 \%)\end{array}$} & $0(0 \%)$ & 5 & $2(9.5 \%)$ & \\
\hline & & B2 & & $1(5 \%)$ & $(23.8 \%)$ & $3(14.3 \%)$ & \\
\hline & \multirow[b]{2}{*}{$\mathrm{C}$} & C1 & \multirow{2}{*}{$\begin{array}{c}13 \\
(65 \%)\end{array}$} & $11(55 \%)$ & 8 & $2(9.5 \%)$ & \\
\hline & & $\mathrm{C} 2$ & & $2(10 \%)$ & $(38.1 \%)$ & $6(28.6 \%)$ & \\
\hline \multirow{2}{*}{$\begin{array}{l}\text { Type of fracture } \\
\text { (no (\%)) }\end{array}$} & \multicolumn{2}{|c|}{ closed } & \multicolumn{2}{|c|}{$19(95 \%)$} & \multicolumn{2}{|c|}{$21(100 \%)$} & \multirow{2}{*}{0.29} \\
\hline & & & & & & 0 & \\
\hline \multirow{4}{*}{$\begin{array}{l}\text { Comorbidity } \\
\text { (no }(\%))\end{array}$} & \multicolumn{2}{|c|}{ T2DM } & \multicolumn{2}{|c|}{$\frac{1(5 \%)}{2(10 \%)}$} & \multicolumn{2}{|c|}{$4(19.1 \%)$} & \multirow{4}{*}{0.131} \\
\hline & \multirow{2}{*}{\multicolumn{2}{|c|}{$\begin{array}{l}\text { HTN } \\
\text { IHD }\end{array}$}} & & 0 & $2(9$ & $5 \%)$ & \\
\hline & & & $2(1$ & $0 \%)$ & & 0 & \\
\hline & & & & $5 \%)$ & & 0 & \\
\hline & Thor & plint & $9(4$ & $5 \%)$ & $4(1$ & $.0 \%)$ & \\
\hline $\begin{array}{l}\text { Type of the } \\
\text { immobilisation }\end{array}$ & Surfa & action & & 0 & $5(2$ & $.8 \%)$ & 002 \\
\hline 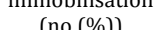 & Exter & ixator & & 0 & & $\%)$ & 10.02 \\
\hline & Lon & slab & $11(5$ & $55 \%)$ & $12(5$ & $7.1 \%)$ & \\
\hline $\begin{array}{r}\text { Duration to su } \\
\text { (rang }\end{array}$ & $\begin{array}{l}\text { sery (N } \\
\text { ) days }\end{array}$ & $\pm \mathrm{SD}$ & $5.4 \pm 2$ & $7(2-12)$ & $6 \pm 3$ & $3(3-18)$ & 0.5 \\
\hline
\end{tabular}

\begin{tabular}{|c|c|c|c|c|}
\hline \multirow{2}{*}{\multicolumn{2}{|c|}{ Variables }} & \multicolumn{2}{|c|}{ Approach to fixation } & \multirow{2}{*}{$\mathbf{p}$} \\
\hline & & ORIF $(n=20)$ & $\operatorname{MIPO}(n=21)$ & \\
\hline \multicolumn{2}{|c|}{$\begin{array}{l}\text { Knee ROM start (mean } \pm \text { SD) } \\
\text { (range) weeks }\end{array}$} & $4.9 \pm 1.2(2-6)$ & $3.5 \pm 1.6(1.5-6)$ & $<.001$ \\
\hline \multicolumn{2}{|c|}{$\begin{array}{l}\text { Full weight bearing start } \\
\text { (mean } \pm \text { SD (range)) weeks }\end{array}$} & $15.6 \pm 3.8(10-24)$ & $15.4 \pm 3.7(10-24)$ & 0.88 \\
\hline \multicolumn{2}{|c|}{$\begin{array}{c}\text { Knee flexion at } 6 \text { weeks(mean } \pm \\
\text { SD(range }))^{\circ}\end{array}$} & $28 \pm 11.5(20-70)$ & $33.3 \pm 7.3(20-40)$ & 0.08 \\
\hline \multicolumn{2}{|c|}{$\begin{array}{l}\text { Knee flexion at } 1 \text { year }(\text { mean } \pm \\
\operatorname{SD}(\text { range }))^{\circ}\end{array}$} & $89.5 \pm 17.3(60-120)$ & $111.4 \pm 15.3(90-130)$ & $<.001$ \\
\hline \multicolumn{2}{|c|}{ Knee flexion $>90^{\circ}$ (no (\%)) } & $7(35 \%)$ & $18(85.7 \%)$ & $<.001$ \\
\hline \multicolumn{2}{|c|}{ Knee flexion $>110^{\circ}$ (no (\%)) } & $2(10 \%)$ & $8(38.1 \%)$ & 0.04 \\
\hline \multicolumn{2}{|c|}{$\begin{array}{l}\text { VAS score at } 6 \text { weeks(mean } \pm \text { SD, } \\
\text { median(range)) }\end{array}$} & $6.9 \pm 1.1,7(5-8)$ & $6.2 \pm 0.7,6(5-8)$ & 0.02 \\
\hline \multicolumn{2}{|c|}{$\begin{array}{l}\text { VAS score at } 1 \text { year(mean } \pm \text { SD, } \\
\text { median(range) })\end{array}$} & $3.3 \pm 1.3,4(0-5)$ & $2.8 \pm 0.5,3(2-4)$ & 0.14 \\
\hline \multirow{2}{*}{$\begin{array}{l}\text { Union at } 6 \\
\text { months }\end{array}$} & callus & $18(90 \%)$ & $21(100 \%)$ & \multirow{2}{*}{0.137} \\
\hline & No callus & $2(10 \%)$ & 0 & \\
\hline \multirow{2}{*}{$\begin{array}{l}\text { Union at } \\
1 \text { year }\end{array}$} & united & $18(90 \%)$ & $21(100 \%)$ & \multirow{2}{*}{0.137} \\
\hline & Implant failure & $2(10 \%)$ & 0 & \\
\hline \multirow{2}{*}{$\begin{array}{l}\text { Deformity at } \\
1 \text { year }\end{array}$} & $10^{\circ} \mathrm{FFD}$ & $1(5 \%)$ & 0 & \multirow{2}{*}{0.544} \\
\hline & varus & 0 & $3(14.29 \%)$ & \\
\hline \multicolumn{5}{|c|}{$\begin{array}{l}\text { Table 2. Summary and Comparison of Outcome Parameters } \\
\text { in ORIF and MIPO Group }\end{array}$} \\
\hline
\end{tabular}

There was mean difference of 11.3 years between the two groups which was significant by t-test. There was no difference in the distribution of gender, co-morbidities, various AO type of fracture (A, B and C) and closed or open fracture among the open reduction and MIPO groups. Mean duration to surgery was also comparable between the two groups. However initial immobilisation method varied between the groups. Postoperative knee ROM was started at an average of 4.2 weeks while full weight bearing was started at an average of 15.5 weeks. Average knee flexion assessed at 6 weeks was $30.7^{\circ}$ (range $20^{\circ}-70^{\circ}$ ) which improved to $100.7^{\circ}$ (range $60^{\circ}$ $130^{\circ}$ ) at 1 year. $61 \%$ patients had $>90^{\circ}$ knee flexion and $24.4 \%$ had $>110^{\circ}$ knee flexion at 1 year. The average VAS score at 6 
weeks was 6.6 (range 5-8) and this significantly decreased to 3 (range $0-5$ ) at 1 year. There was 1 case with $10^{\circ}$ Fixed flexion deformity and 3 cases with varus deformity at 1 year. Radiological union was defined as presence of bridging callus across three cortices. Of 41 patients, there was presence of callus at 6 months in 39 patients and all of them had united by 1 year. In 2 patients, there was no callus seen at 6 months and these went on to implant failure at 1 year. The comparison of outcome parameters and complications for the two groups is summarized in table 2.
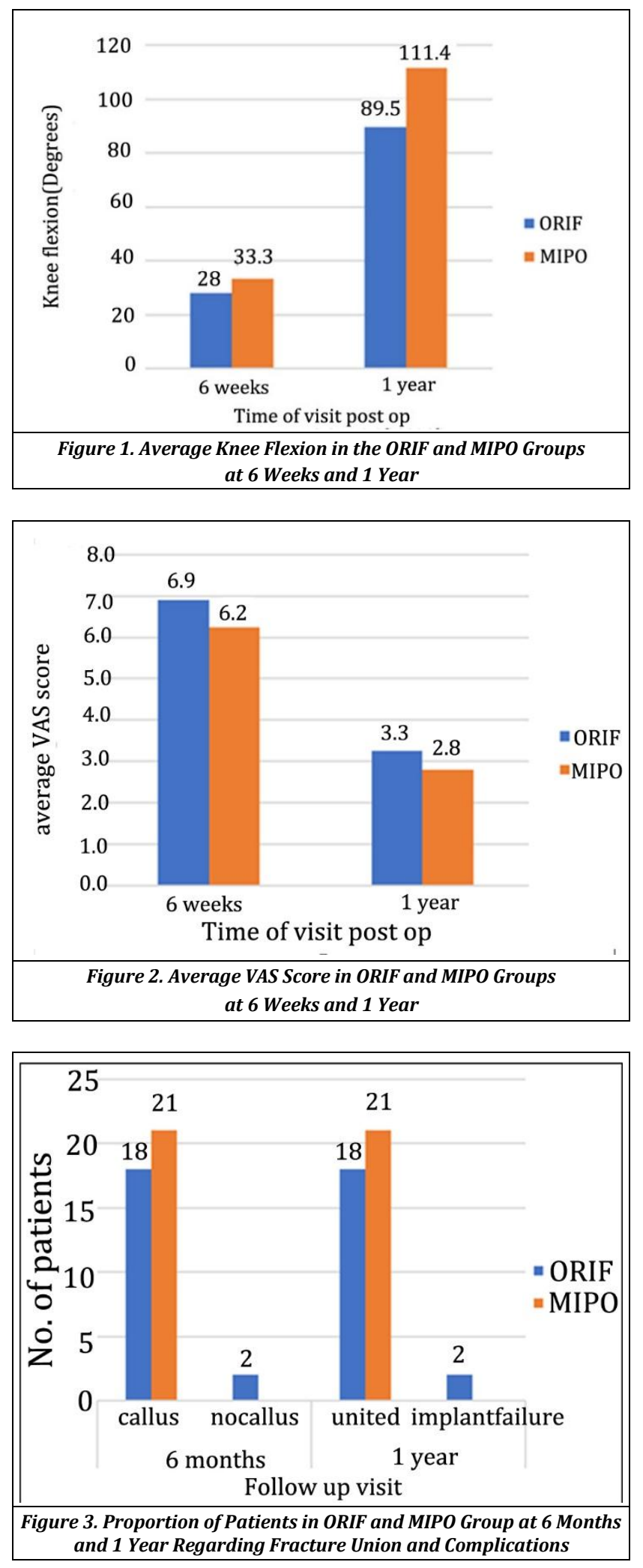

Knee ROM could be started at mean 1.4 weeks earlier in the MIPO group and this was statistically significant. The two groups did not differ significantly in start of full weight bearing. Knee flexion at 6 weeks was also comparable in the two groups. However, the knee flexion was average $21.9^{\circ}$ higher in MIPO group at 1 year which was significantly different than ORIF group. The proportion of patients with $>90^{\circ}$ and $>110^{\circ}$ knee flexion also varied significantly between the groups. VAS score in MIPO group was significantly less at 6 weeks but difference was non-significant at 1 year. There were 2 cases with non-union and implant failure in the ORIF group, but the proportion was not significant. There was $10^{\circ}$ FFD in 1 patient of ORIF group, while varus deformity occurred in 3 patients of MIPO group. The proportions of deformity were not significantly different between the two groups.

\section{DISCUSSION}

Distal femur fracture is a complex, challenging injury due to nearby knee joint involvement. There is consensus regarding surgical treatment due to complications like angular deformities, non-union and problems of prolonged immobilisation live DVT, PE, sores, stiffness and functional loss. ${ }^{6}$ Zhongguogushang et al concluded that this method for treatment of supracondylar femur fracture can get satisfactory function, high rate of bone union and fewer complications. Familiarity with the close reduction technique and the geometry shape of anatomic plate as well as femoral supracondylar area are important to treat the supracondylar femur fractures. In his study of 39 supracondylar fractures treated by MIPPO 28 got excellent, 10 got good and remaining got fair results. ${ }^{23}$ Regarding optimal methods of management, there is still controversy among treating surgeons and lack of uniform clinical guidelines.

In our study, mean age of patients was $48.1 \pm 13.5$ year in ORIF group and $59.3 \pm 12.1$ year in MIPO group. The two groups did not differ significantly with respect to epidemiologic variables and time to surgery. With rise in motor vehicle accidents younger patients had sustained fractures, which is similar to other studies showing bimodal age distribution according to injury mechanism. ${ }^{24}$ Male: Female ratio was 1:1 in ORIF group and 4:3 in MIPO group. Most of the patients had AO C type fracture in both the groups. There was one open fracture which was Gustilo-Anderson type 1 in the ORIF group. $10 \%$ of patients in ORIF group and $19 \%$ in MIPO group had well controlled Type 2 Diabetes. Initial immobilisation was done in long leg slab for most patients. Two patients in MIPO group had External fixator applied due to soft tissue condition. Fixator was removed within 1 week once soft tissue condition improved. Mean duration to surgery was $5.4 \pm 2.7$ days in ORIF group and $6 \pm 3.3$ in MIPO group. The VAS pain score was comparable in the two groups postoperatively, however patients in MIPO group had started knee ROM at average 3.5 weeks compared to 4.9 weeks for ORIF group. Early mobilization promotes fracture healing and reduces incidence of joint stiffness. But due to fracture comminution in most cases delayed weight bearing was given.

The LCP is a a single beam construct where the strength of its fixation is equal to the sum of all screw- bone interfaces rather than a single screw's axial stiffness and pull out 
resistance in unlocked plates. ${ }^{15}$ Its unique biomechanical function is based on splinting rather than compression resulting in flexible stabilization, avoidance of stress shielding and induction of callus formation. When applied via a minimally invasive technique, it allows for prompt healing, lower rates of infection and reduced bone resorption as blood supply is preserved. In the study by Schutz, Muller et al ${ }^{14}$ the internal fixation using LISS was done 5 days after the injury and there was $5 \%$ non-union rate. In our study there were 2 cases of implant failure due to non-union in the ORIF group, while all patients in MIPO group had healed fracture. On analysing it retrospectively we believe the cause for implant failure was initial fracture comminution (C1) which led to gap non-union.

Laubenthal has demonstrated that average motion required for: Normal sitting- 93-degree, stair climbing -100degree, squatting- 117 degree. Thus, acceptable knee flexion compatible with daily activity would be around 110 degree. In our study, mean knee flexion was $89.5 \pm 17.3$ degree in ORIF group vs $111.4 \pm 15.3$ degree in MIPO group. Only $10 \%$ patients had ROM>110 degree in ORIF group. In this study it has been observed that the operative technique respecting the biology and biomechanical principles have shown success in treating distal femur fractures. It is of utmost importance that the muscle and periosteal bone cover are preserved, in case of comminution, free fragments must be untouched. With a biological fixation technique, blood flow remains intact and bone healing is not disturbed. In consideration to biomechanical principles, using long plates, bicortical screws, optimal plate hole to screw ratio and not to create too rigid construct. Careful intraoperative attention should be given to restoring alignment in all planes. Restoration of both medial and lateral columns is necessary to prevent complication. In our study there was 10-degree fixed flexion deformity in 1 patient in ORIF group while 3 patients in MIPO group had Varus deformity. None of our patients had deep surgical infection.

In a study by Doshi et al and a similar study conducted by Khursheed et al on clinical outcomes of distal femoral fractures in geriatric population using locking plates with a minimally invasive approach they concluded that it resulted in a favourable outcome and the method appears to be useful and safe. All patients in their study had satisfactory functional outcomes with no mortalities and few postoperative complications. ${ }^{25,16}$

Our results are comparable with the previous literature by Nayak et al. They evaluated treatment outcomes of minimally invasive plate osteosynthesis for distal femoral fractures in 31 patients, found $93.54 \%$ patients had good or excellent outcomes with radiological union grade-I \& II and the mean time to union was achieved in 3.7 (range, 2.8-4.6) months. None of the patients had patient had angular or rotational deformity of $>10.26$

\section{CONCLUSIONS}

Closed reduction and pre-contoured LCP plating for distal femur by MIPO is a soft tissue friendly approach preserving blood supply and can get satisfactory function, high rate of bone union with fewer complications, minimizing the use of bone grafting and donor site complications. It provides rigid fixation in the region of femur, where widened canal, thin cortices and frequently poor bone stock makes fixation difficult. Locking compression plating by MIPO technique is an important procedure in treatment of distal femur fractures especially when fracture is severely comminuted and in situations of osteoporosis.

\section{ACKNOWLEDGEMENT}

Authors acknowledge the contribution of the whole orthopaedic department, OT technicians, staff and the governing authority of Ramakrishna Mission Seva Pratishthan.

\section{REFERENCES}

[1] Court-Brown CM, Caesar B. Epidemiology of adult fractures: a review. Injury 2006;37(8):691-7.

[2] Martinet O, Cordey J, Harder Y, et al. International Journal of Orthopaedics Sciences Barraud GE. The epidemiology of fractures of the distal femur. Injury 2000;31(3):C62-C3.

[3] Wahnert D, Hoffmeier K, Frober R, et al. Distal femur fractures of the elderly-different treatment options in a biomechanical comparison. Injury 2011;42(7):655-9.

[4] Fankhauser F, Gruber G, Schippinger G, et al. Minimalinvasive treatment of distal femoral fractures with the LISS (Less Invasive Stabilization System). A prospective study of 30 fractures with a follow up of 20 months. Acta Orthop Scand 2004;75(1):55-60.

[5] Ehlinger M, Adam P, Arlettaz Y, et al. Minimally-invasive fixation of distal extra-articular femur fractures with locking plates: Limitations and failures. Orthop Traumatol Surg Res 2011;97(6):668-74.

[6] Rockwood CA, Green DP, Bucholz RW, et al. Rockwood and Green's Fractures in adults. $4^{\text {th }}$ edn. Philadelphia, New York: Lippincott Raven 1996.

[7] Browner BD, Jupiter JB, Levine AM, et al. Skeletal trauma-fractures, dislocations, ligamentous injuries. $2^{\text {nd }}$ edn. Philadelphia, London, Toronto, Montreal, Sydney, Tokyo: W.B. Saunders 1998.

[8] Bernstein J, Monaghan BA, Silber JS, et al. Taxonomy and treatment-a classification of fracture classifications. J Bone Joint Surg Br 1997;79(5):706-7.

[9] Müller ME, Nazarian S, Koch P, et al. The comprehensive classification of fractures of long bones. $1^{\text {st }}$ edn. Berlin, Heidelberg, New York: Springer Verlag 1990.

[10] Audige L, Bhandari M, Kellam J. How reliable are studies of fracture classifications? A systemic review of their methodologies. Acta Orthop Scand 2004;75(2):184-94.

[11] Orozco R, Sales JM, Videla M. Atlas of internal fixation. Fractures of long bones. $1^{\text {st }}$ edn. Berlin, Heidelberg, New York: Springer Verlag 2000.

[12] Yeap EJ, Deepak AS. Distal femoral locking compression plate fixation in distal femoral fractures: early results. Malaysian Orthopaedic 2007;1(1):12-7. 
[13] Sahoo BS, Chand DK, et al. Distal femur fracture fixation by LCP- 2 year experience. International Journal of Orthopaedics Sciences 2017;3(1):814-8.

[14] Schutz M, Muller M, Regazzoni P, et al. Use of the Less Invasive Stabilization System (LISS) in patients with distal femoral (A033) fractures: a prospective multicenter study. Arch Orthop Trauma Surg 2005;125(2):102-8.

[15] Kregor PJ, Stannard J, Zlowodzki M, et al. Distal femoral fracture fixation utilizing the Less Invasive Stabilization System (L.I.S.S.): the technique and early results. Injury 2001;(32 Suppl 3):SC32-47.

[16] Khursheed O, Wani MM, Rashid S, et al. Results of treatment of distal extra: articular femur fractures with locking plates using minimally invasive approach-experience with 25 consecutive geriatric patients. Musculoskelet Surg 2015;99(2):139-47.

[17] Krettekl C, Miillerz M, Miclaus T, et al. Evolution of Minimally Invasive Plate Osteosynthesis (MIPO) in the femur. Int J Care Inj 2001;32(3):14-23.

[18] Smith TO, Hedges C, MacNair R, et al. The clinical and radiological outcomes of the LISS plate for distal femoral fractures: A systematic review. Injury 2009;40(10):104963.

[19] Malik AL, Siddique M, Niazi NS, et al. Outcome of locking compression plate in supracondylar fracture of distal femur by minimally invasive plate osteosynthesis. Pakistan J Med Heal Sci 2015;9(1):31-3.
[20] Jain JK, Asif N, Ahmad S, et al. Locked compression plating for peri- and intra-articular fractures around the knee. Orthop Surg 2013;5(4):255-60.

[21] El-Ganainy AR, Elgeidi A. Treatment of distal femoral fractures in elderly diabetic patients using minimally invasive percutaneous plating osteosynthesis (MIPPO). Acta Orthop Belg 2010;76(4):503-6.

[22] Necmioglu NS, Subasi M, Kayikci C. Minimally invasive plate osteosynthesis in the treatment of femur fractures due to gunshot injuries. Acta Orthop Traumatol Turc 2005;39(2):142-9.

[23] Liu XD, Wang XB, Xu Q, et al. Close reduction by manipulation and minimally invasive percutaneous plate osteosynthesis for the treatment of supracondylar femur fractures. Zhongguo Gu Shang 2011;24(8):693-4.

[24] Raghu KJ, Anaberu P, Oswal VM. Minimally invasive plate osteosynthesis of lower end of femur fractures using locking compression plating: a prospective study. Int J Res Orthop 2017;3(5):1043-50.

[25] Doshi HK, Wenxian P, Burgula MV, et al. Clinical outcomes of distal femoral fractures in the geriatric population using locking plates with a minimally invasive approach. Geriatr Orthop Surg Rehabil 2013;4(1):16-20.

[26] Nayak RM, Koichade MR, Umre AN, et al. Minimally invasive plate osteosynthesis using a locking compression plate for distal femoral fractures. J Orthop Surg (Hong Kong) 2011;19(2):185-90. 